\title{
Spontaneous uterine vessel perforation in late pregnancy following in vitro fertilisation: a rare cause of near miss maternal morbidity and fetal death
}

\author{
Shalini Gainder, Tanuja Muthyala*, Subhas Chandra Saha
}

Department of Obstetrics and Gynecology, Post Graduate Institute of Medical Education and Research, Chandigarh, India

Received: 12 June 2015

Accepted: 27 October 2015

\author{
*Correspondence: \\ Dr. Tanuja Muthyala, \\ E-mail: drtanujambbs@gmail.com
}

Copyright: (c) the author(s), publisher and licensee Medip Academy. This is an open-access article distributed under the terms of the Creative Commons Attribution Non-Commercial License, which permits unrestricted non-commercial use, distribution, and reproduction in any medium, provided the original work is properly cited.

\begin{abstract}
Spontaneous perforation of uterine vessels causing hemoperitoneum in pregnancy is rare and is associated with high perinatal and maternal mortality and morbidity. However, for the clinician identification of aetiology with ongoing resuscitation is important in order to affect the proper treatment. Case report: We report a case of spontaneous hemoperitoneum in pregnancy following IVF conception due to ruptured uterine vein successfully managed with emergency laparotomy and repair of the uterine vessel. Conclusion: Clinicians should be aware of such rare and potentially fatal complications after IVF, because early diagnosis and management in these cases can yield a favourable maternal and perinatal outcome.
\end{abstract}

Keywords: Hemoperitoneum, IVF conception, Laparotomy, Perforated uterine vein

\section{INTRODUCTION}

The spontaneous rupture of the uterine vessels in pregnancy or postpartum is rare with an incidence of 1 in 10,000 pregnancies. ${ }^{1}$ Till date only few cases have been reported in literature, but majority of them were following spontaneous conception. It often presents as a life-threatening emergency with acute abdomen accompanied by signs of hypovolemic shock, fall in haemoglobin levels and fetal distress in the antenatal period and as haemorrhagic shock in the postpartum period. Ultrasonography shows hemoperitoneum with no identifiable cause. We report a case of spontaneous hemoperitoneum in pregnancy following IVF conception due to ruptured uterine vein successfully treated with emergency laparotomy and repair of the uterine vessel. High index of suspicion of this rare diagnosis is to be kept with ongoing resuscitation when no other cause is attributable. Uterine artery embolisation is an option available in hemodynamically stable patients.

\section{CASE REPORT}

A 33-year-old woman with twin gestation at 32 weeks period of gestation was referred to our centre with severe anaemia. It was an IVF conception for unexplained infertility. Her pregnancy was apparently uncomplicated till 32 weeks when she developed acute pain abdomen for which she was hospitalized. During evaluation, she developed respiratory distress and fall in hemoglobin level to $6 \mathrm{gm} \%$ when she was referred to our centre. She was in hypovolaemic shock with metabolic acidosis and required assisted ventilation. Ultrasonography shown twin intrauterine fetus with both having no cardiac activity and no free fluid within the peritoneal cavity. She went into spontaneous labour and delivered still born 
babies. There was no improvement in vitals despite resuscitation with colloids and blood products. A repeat ultrasonogram revealed presence of free fluid which was not evidenced previously. Subsequently an exploratory laparotomy was performed which revealed haemoperitoneum of around one litre and bleeding from a ruptured subserosal vein of the uterus (Figure 1).

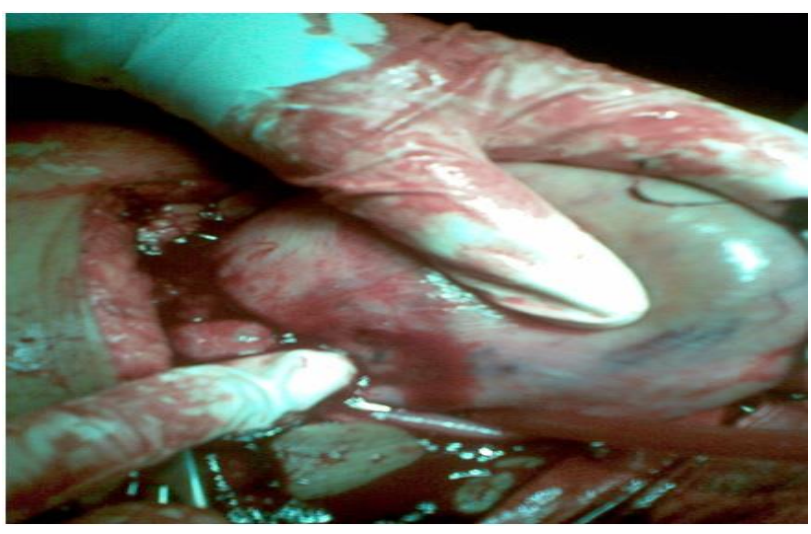

Figure 1: Active bleeding from perforated uterine vein seen during laparotomy.

Haemostatic sutures were applied and bleeding stopped. She received five units of blood, three units of frozen plasma and two units of random platelets. Postoperatively patient recovered and discharged.

\section{DISCUSSION}

When a pregnant woman experiences acute onset, severe abdominal pain even without any history of abdominal trauma both obstetric and non-obstetric causes are to be sought. Intra-abdominal haemorrhage from ruptured uterine vessels is very rare and is a catastrophe which can occur in antepartum or postpartum period. Most of these cases occur antenatally (61\%) especially during the third trimester of pregnancy and more rarely during labor (18\%) or puerpeurium $(21 \%) .^{2}$ The most common places where it happens is the broad ligament $(78.3 \%)$, the back of the uterus $(18.3 \%)$, and the front face of the uterus $(3.3 \%) .{ }^{1}$ The definitive pre-operative diagnosis is often difficult as there is no specific symptom or diagnostic ultra sonographic marker specific to this condition and the diagnosis is often made intra-operatively. Davidson attributed the aetiology of spontaneous rupture to congenital arteriovenous malformation, arterial degeneration and inflammatory processes. ${ }^{3}$ Similar cases of hemoperitoneum secondary to spontaneous rupture of uterine vessels (veins or arteries), uterine varices, or uterine-ovarian vessels are reported but majority of them were following a spontaneous conception. ${ }^{4}$ Thin walled, non-valvular and tortuous course of uterine veins with high pelvic vein pressures during pregnancy are the factors predisposing for rupture. Presence of endometriotic lesions, adhesions, vascular anomalies, previous uterine surgery, uterine fibroids, and multiparity may be considered as risk factors. ${ }^{2,5}$ Chung reported a case of maternal death occurring after spontaneous rupture of a uterine artery immediately following delivery. The patient presented with abdominal pain and collapse one hour after normal delivery. Laparotomy revealed massive hemoperitoneum and intraperitoneal bleeding from the right uterine artery. Ligature of the uterine artery and hysterectomy were performed but the patient died of multiorgan failure 18 hours after the delivery. ${ }^{6}$ Gonzalez reported a case of a 23-year-old woman at 22 weeks of gestation with acute abdomen without traumatic antecedents, and signs of hypovolemic shock. Exploratory laparotomy revealed a laceration in the right uterine artery as the cause of hemoperitoneum. Bleeding vessel was repaired and pregnancy was continued till 38 weeks of gestation. ${ }^{7}$ Gavanier reported a case of spontaneous haemoperitoneum secondary to ruptured uterine artery aneurysm in mid trimester managed by uterine artery embolization. ${ }^{8}$ Aziz reported a case of hemoperitoneum in pregnancy at 20 weeks gestation that resulted from spontaneous rupture of the uterine vessels associated with decidualized endometriosis managed by hysterotomy and repair of the vessel. ${ }^{5}$ Kapila on autopsy confirmed ruptured uterine artery as cause of hemoperitoneum in a 21 year old primigravida at 29 weeks of gestation who was brought dead following acute abdomen with haemorrhagic shock. ${ }^{9}$ Women who undergo IVF treatment may be predisposed to bleeding from uterine vessels during pregnancy caused by aetiology not explained with the available evidence in literature. Possible explanation may be secondary to subclinical infections due to repeated interventions on the uterus, minor degree of trauma to vessels during ovum pickup with added physiological changes during pregnancy and transmission of high pelvic vein pressures. High index of suspicion, institution of effective resuscitative measures and early surgical intervention are essential for both fetal and maternal survival. Percutaneous vascular embolization of the uterine arteries is an alternative and effective treatment in hemodynamically stable patients.

\section{ACKNOWLEDGMENTS}

Authors would like to thank the Institute, author, coauthors who helped author a lot in completing this article successfully.

\section{Funding: No funding sources \\ Conflict of interest: None declared \\ Ethical approval: Not required}

\section{REFERENCES}

1. Andr'es-Or'os MP, Server-de Castro L, Roy-Ramos $\mathrm{V}$, Vela-Lete A. Spontaneous transmission of varicose uterus during gestation. Disruption of two cases and bibliographic review. Microbiol Obstet Mex. 2010;78:128-31. 
2. Ginsburg KA, Valdes C, and Schnider G. Spontaneous three case reports and a review of the literature. Obstet Gynecol. 1987;69:474-6.

3. Davidson MB, Madsen PV, Wilken Jensen. True aneurysm of the uterine artery. Eur J Surg. 1995;161:775-6.

4. Giulini S, Zanin R, Volpe A. Hemoperitoneum in pregnancy from a ruptured varix of broad ligament. Arch Gynecol Obstetrics. 2010;282:459-61.

5. Aziz U, Kulkarni A, Lazic D, Cullimore JE. Spontaneous rupture of the uterine vessels in pregnancy. Obstet Gynecol. 2004;103:1089-91.

6. Chung, FB, Terzibachian JJ, Lovera JC, Grisey A, Leung F, Riethmuller D. Maternal death after spontaneous rupture of a uterine artery immediately following delivery. Gynecol Obstet Fertil. 2008;36:1008-11.

7. González RR, Cerón SMA, Ayala LI, Cerda LJA. Uterine vessels spontaneous rupture during pregnancy. Ginecol Obstet Mex. 2008;76:221-3.
8. Kapila P. Fatal non-traumatic spontaneous hemoperitoneum in second trimester of pregnancyautopsy findings. J Forensic Leg Med. 2011;18:13940.

9. Gavanier D, Orsoni M, Dupuis O, Valette PJ. Spontaneous hemoperitoneum during pregnancy and uterine artery aneurysm. Gynecol Obstet Fertil. 2012;40:711-14.

Cite this article as: Gainder S, Muthyala T, Saha SC. Spontaneous uterine vessel perforation in late pregnancy following in vitro fertilisation: a rare cause of near miss maternal morbidity and fetal death. Int J Reprod Contracept Obstet Gynecol 2017;6:3664-6. 